\title{
Effects of Sodium Nitroprusside on Left Ventricular Diastolic Pressure-Volume Relations
}

\author{
Bruce R. Brodie, William Grossman, Tift Mann, and Lambert P. Mclaurin \\ From the Department of Medicine, University of North Carolina School of Medicine, \\ and the C. V. Richardson Cardiac Catheterization Laboratory, Chapel Hill, North Carolina 27514
}

A B S T R A C T The effect of sodium nitroprusside on the relationship between left ventricular pressure and volume during diastole was studied in 11 patients with congestive heart failure. Nitroprusside was infused to lower mean arterial pressure approximately 20-30 $\mathrm{mm} \mathrm{Hg}$. High fidelity left ventricular pressures were recorded in all patients simultaneously with left ventricular cineangiography (biplane in eight and single plane in three patients), allowing precise measurement of pressure and volume throughout the cardiac cycle. Left ventricular diastolic pressurevolume curves were constructed in each patient from data obtained before and during nitroprusside infusion. In 9 of 11 patients there was a substantial downward displacement of the diastolic pressure-volume curve during nitroprusside infusion, with left ventricular pressure being lower for any given volume with nitroprusside. Serial left ventricular cineangiograms performed $15 \mathrm{~min}$ apart in six additional subjects who did not receive sodium nitroprusside showed no shift in the diastolic pressure-volume relation, indicating that the shift seen with nitroprusside was not due to the angiographic procedure itself. A possible explanation for the altered diastolic pressure-volume relationships with nitroprusside might be a direct relaxant effect of nitroprusside on ventricular muscle, similar to its known relaxant effect on vascular smooth muscle. Alternatively, nitroprusside may affect the diastolic pressure-volume curve by affecting viscous properties or by altering one or more of the extrinsic constraints acting upon the left ventricle.

\section{INTRODUCTION}

Sodium nitroprusside has been employed in the treatment of hypertensive states for many years (1-4),

Dr. Grossman was an Established Investigator of the American Heart Association.

Received for publication 8 March 1976 and in revised form 16 July 1976. and recently, its therapeutic application has been extended to the treatment of left ventricular failure complicating acute myocardial infarction $(5,6)$, mitral regurgitation (7-10), aortic regurgitation (11), and chronic heart failure from ischemic or primary myocardial disease $(11,12)$. A fall in the left ventricular filling pressure has been a consistent finding in all studies. This has been attributed to smaller ventricular volumes resulting from reduction in afterload (with better systolic emptying) and preload (due to venous dilatation), but demonstration that the lower filling pressures are in fact a consequence of smaller ventricular volumes has not been reported. Although there have been a number of studies concerning the effects of sodium nitroprusside on left ventricular systolic performance (5-14), little is known about its effects on left ventricular diastolic properties. To explore the possibility that nitroprusside might be lowering ventricular filling pressures by altering the diastolic properties of the left ventricle, we examined the left ventricular diastolic pressure-volume relationship in 11 patients with congestive heart failure before and during the administration of sodium nitroprusside. The results indicate that sodium nitroprusside is capable of producing a substantial downward shift of the left ventricular diastolic pressure-volume curve, and that factors in addition to a reduction in diastolic volume are responsible for the lowering of ventricular filling pressures in patients with congestive heart failure treated with nitroprusside.

\section{METHODS}

Patient population. Patients with clinical evidence of congestive heart failure scheduled to undergo routine diagnostic cardiac catheterization in our laboratory were invited to participate in the study. The experimental protocol was approved by the Committee on the Rights of Human Subjects at our institution and informed consent was obtained from all patients. Patients with conditions known to affect the left ventricle in an asymmetrical way (such as coronary artery disease and idiopathic hypertrophic subaortic stenosis) were 
TABLE I

Hemodynamic and Angiographic Data before

\begin{tabular}{|c|c|c|c|c|c|c|c|c|c|c|c|c|}
\hline \multirow[t]{2}{*}{ Pt.* } & \multicolumn{2}{|l|}{ Dx. } & \multirow{2}{*}{$\frac{\mathrm{CO}}{\text { liters/min }}$} & HR & SA & LVEDP & LVMDP & PAW & $\mathrm{PA}$ & $\mathrm{RA}$ & SVR & PVR \\
\hline & & & & \multicolumn{2}{|l|}{ beats/min } & \multicolumn{4}{|c|}{$m m H_{g}$} & & \multicolumn{2}{|c|}{$d ! y n-s / c m^{5}$} \\
\hline \multirow[t]{2}{*}{1} & \multirow[t]{2}{*}{ MR } & $\mathrm{C}$ & 3.9 & 75 & 100 & 23 & 10 & 27 & 37 & 9 & 1,867 & 205 \\
\hline & & NTP & 4.7 & 75 & 80 & 8 & 0 & 11 & 22 & 6 & 1,260 & 187 \\
\hline \multirow[t]{2}{*}{2} & $\mathrm{CM}$ & $\mathrm{C}$ & 6.3 & 60 & 100 & 27 & 14 & 16 & 22 & 12 & 1,117 & 76 \\
\hline & & NTP & 7.8 & 72 & 86 & 9 & 0 & 12 & 14 & 9 & 790 & 21 \\
\hline \multirow[t]{2}{*}{3} & AR & $\mathrm{C}$ & 5.1 & 72 & 105 & 32 & 21 & 22 & 30 & 2 & 1,616 & 125 \\
\hline & & NTP & 4.9 & 80 & 90 & 7 & 0 & 2 & 7 & 0 & 1,469 & 82 \\
\hline \multirow[t]{2}{*}{4} & MR & $\mathrm{C}$ & 3.6 & 80 AF & 90 & 20 & 16 & 24 & 35 & 9 & 1,800 & 244 \\
\hline & & NTP & 5.0 & $87 \quad \mathrm{AF}$ & 65 & 13 & 4 & 14 & 22 & 8 & 912 & 128 \\
\hline \multirow[t]{2}{*}{5} & MR & $\mathrm{C}$ & 3.7 & 120 & 88 & 16 & 8 & 28 & 42 & 10 & 1,686 & 303 \\
\hline & & NTP & 4.8 & 72 & 60 & 13 & 3 & 16 & 24 & 10 & 833 & 133 \\
\hline \multirow[t]{2}{*}{6} & $\mathrm{CM}$ & $\mathrm{C}$ & 3.2 & 78 & 84 & 23 & 10 & 13 & 18 & 6 & 1,950 & 125 \\
\hline & & NTP & 3.6 & 87 & 68 & 16 & 6 & 9 & 13 & 3 & 1,444 & 89 \\
\hline \multirow[t]{2}{*}{7} & MR & C & 6.2 & 97 & 88 & 30 & 5 & 28 & 33 & 7 & 1,045 & 65 \\
\hline & & NTP & 9.5 & 102 & 60 & 11 & 1 & 10 & 20 & 4 & 472 & 84 \\
\hline \multirow[t]{2}{*}{8} & MR & $\mathrm{C}$ & 4.8 & 90 & 90 & 14 & 7 & 7 & 11 & 3 & 1,450 & 67 \\
\hline & & NTP & 4.9 & 84 & 72 & 8 & 3 & 5 & 10 & 2 & 1,143 & 82 \\
\hline \multirow[t]{2}{*}{9} & AR & $\mathrm{C}$ & 5.5 & 76 & 90 & 8 & 3 & 10 & 14 & 3 & 1,265 & 58 \\
\hline & & NTP & 4.6 & 84 & 65 & 5 & 0 & 4 & 9 & 2 & 1,096 & 87 \\
\hline \multirow[t]{2}{*}{10} & MR & $\mathrm{C}$ & 6.5 & $114 \mathrm{AF}$ & 130 & 6 & 2 & 16 & 20 & 6 & 1,526 & 49 \\
\hline & & NTP & 3.9 & $102 \mathrm{AF}$ & 65 & 4 & 0 & 6 & 11 & 2 & 1,292 & 103 \\
\hline \multirow[t]{2}{*}{11} & AR & $\mathrm{C}$ & 6.9 & 84 & 130 & 14 & 4 & 8 & 15 & 2 & 1,484 & 81 \\
\hline & & NTP & 10.9 & 96 & 80 & 7 & 2 & 4 & 9 & 1 & 587 & 37 \\
\hline \multirow[t]{2}{*}{ Mean \pm SEM } & & $\mathrm{C}$ & $5.1 \pm 0.4$ & $86 \pm 5$ & $100 \pm 5$ & $19 \pm 3$ & $9 \pm 2$ & $18 \pm 2$ & $25 \pm 3$ & $7 \pm 1$ & $1,528 \pm 89$ & $127 \pm 26$ \\
\hline & & NTP & $5.9 \pm 0.8$ & $86 \pm 3$ & $72 \pm 3$ & $9 \pm 1$ & $2 \pm 1$ & $9 \pm 1$ & $15 \pm 2$ & $4 \pm 1$ & $1,027 \pm 101$ & $94 \pm 14$ \\
\hline$P$ value & & & NS & NS & $<0.001$ & $<0.005$ & $<0.005$ & $<0.001$ & $<0.001$ & $<0.001$ & $<0.001$ & NS \\
\hline
\end{tabular}

* Pt.-patient; Dx.-diagnosis; C-control; NTP-nitroprusside; CM-cardiomyopathy; MR-mitral regurgitation; AR-aortic regurgitation; CO-cardiac output; HR-heart rate; SA-mean systemic arterial pressure; LVEDP-left ventricular end-diastolic pressure; LVMDP - left ventricular minimal diastolic pressure; PAW - mean pulmonary artery wedge pressure; PA-mean pulmonary artery pressure; RA-mean right atrial pressure; SVR_systemic vascular resistance; PVR_pulmonary vascular resistance; AF_atrial fibrillation.

excluded. The study group thus obtained consisted of 11 patients, including 2 patients with hypertrophic cardiomyopathy, 5 patients with chronic mitral regurgitation due to rheumatic heart disease, 1 patient with acute mitral regurgitation due to bacterial endocarditis, 2 patients with aortic regurgitation due to rheumatic heart disease, and 1 patient with idiopathic aortic regurgitation. Hemodynamic and angiographic data for each patient are detailed in Table I. In addition, six patients were studied with serial left ventricular cineangiography, as described below, but did not receive sodium nitroprusside. Two of these patients had severe congestive cardiomyopathy thought to be secondary to alcohol abuse, one patient had aortic stenosis and insufficiency with congestive heart failure due to congenital heart disease and three patients had no evidence of organic heart disease (chest pain syndromes with angiographically normal coronary arteries and normal hemodynamics). These subjects served as controls to evaluate the effect of the contrast media itself on left ventricular diastolic properties.

Methods and equipment. Cardiac catheterization was performed in the fasting state using the right brachial arteriotomy approach after premedication with diazepam
(10 mg i.m., Valium, Roche Laboratories, Nutley, N. J.). Left ventricular pressure was recorded using high fidelity micromanometer-tipped catheters ${ }^{1}$ in all patients to permit accurate measurement of ventricular pressure simultaneously with the performance of cineangiography. The patients were instructed to avoid deep respirations and the Valsalva maneuver during the cineangiogram and recording of pressures. The first derivation of left ventricular pressure $(\mathrm{d} P / \mathrm{d} t)$ was obtained using a passive (resistance capacitance) differentiating circuit with a 0.5 -ms time constant and an output linearly proportional to the input frequency, within $5 \%$, up to a rated maximal frequency of $75 \mathrm{~Hz}$. Left ventricular cineangiograms were performed with the injection of 30-50 $\mathrm{cm}^{3}$ of radiographic contrast material (75\% Hypaque-M, Pharmacia Fine Chemicals Inc., Piscataway, N. J.) into the ventricular chamber at a rate of $12-15 \mathrm{~cm}^{3}$ per s. A Siemens cesium iodide image intensifier was used (Siemens Corp., Medical/Industrial Groups, Iselin, N. J.), and cineangiograms were recorded on $35 \mathrm{~mm}$ film at 56 frames per s.

\footnotetext{
${ }^{1}$ Mikrotip, Millar Instruments, Houston, Tex.
} 
and during Sodium Nitroprusside Infusion

\begin{tabular}{|c|c|c|c|c|c|c|c|c|}
\hline$+\mathrm{d} P / \mathrm{d} t t$ & $-\mathrm{d} P / \mathrm{d} t$ & EDV & ESV & $\mathrm{EF}$ & $\mathrm{DFR}_{\mathrm{f}}$ & $\mathrm{DFR}_{\mathrm{u}}$ & $\mathrm{DFR}_{1}$ & $\overline{\mathrm{DFR}}$ \\
\hline \multicolumn{2}{|c|}{$\mathrm{mm} \mathrm{Hg} / \mathrm{s}$} & \multicolumn{2}{|c|}{$m l$} & & \multicolumn{4}{|c|}{$\mathrm{ml} / \mathrm{s}$} \\
\hline- & - & 313 & 106 & 0.66 & 981 & 574 & 777 & 719 \\
\hline- & - & 248 & 60 & 0.76 & 576 & 350 & 292 & 402 \\
\hline- & - & 202 & 43 & 0.79 & 451 & 528 & 257 & 402 \\
\hline- & - & 170 & 48 & 0.72 & 389 & 463 & 278 & 377 \\
\hline 1,404 & 1,264 & 445 & 270 & 0.39 & 486 & 417 & 555 & 486 \\
\hline 1,544 & 1,404 & 353 & 175 & 0.50 & 299 & 465 & 472 & 412 \\
\hline 1,818 & 1,364 & 442 & 145 & 0.67 & 1,759 & 713 & 417 & 1,031 \\
\hline 1,932 & 1,364 & 410 & 135 & 0.67 & 1,833 & 1,250 & 490 & 1,091 \\
\hline- & - & 320 & 157 & 0.51 & 843 & 625 & 250 & 566 \\
\hline- & - & 315 & 117 & 0.63 & 1,292 & 1,111 & 347 & 917 \\
\hline 1,428 & 902 & 155 & 70 & 0.55 & 278 & 296 & 213 & 262 \\
\hline 1,428 & 827 & 141 & 62 & 0.56 & 194 & 257 & 130 & 199 \\
\hline 2,250 & 1,625 & 163 & 58 & 0.64 & 792 & 458 & 208 & 486 \\
\hline 2,500 & 1,438 & 168 & 40 & 0.76 & 555 & 417 & 213 & 395 \\
\hline 1,538 & 1,348 & 250 & 62 & 0.75 & 1,019 & 583 & 417 & 653 \\
\hline 1,201 & 1,494 & 199 & 56 & 0.72 & 704 & 306 & 315 & 441 \\
\hline 1,429 & 1,295 & 370 & 216 & 0.42 & 528 & 361 & 315 & 475 \\
\hline 1,072 & 1,075 & 377 & 229 & 0.39 & 493 & 306 & 306 & 374 \\
\hline- & - & 393 & 218 & 0.45 & 889 & 1,361 & 361 & 972 \\
\hline - & - & 395 & 198 & 0.50 & 430 & 954 & 296 & 547 \\
\hline 2,273 & 1,936 & 345 & 200 & 0.42 & 875 & 792 & 231 & 575 \\
\hline 2,233 & 1,146 & 295 & 170 & 0.42 & 444 & 597 & 250 & 434 \\
\hline $1,734 \pm 146$ & $1,391 \pm 121$ & $309 \pm 31$ & $140 \pm 24$ & $0.57 \pm 0.04$ & $809 \pm 120$ & $592 \pm 90$ & $364 \pm 53$ & $602 \pm 70$ \\
\hline $1,701 \pm 202$ & $1,250 \pm 91$ & $279 \pm 30$ & $117 \pm 21$ & $0.60 \pm 0.04$ & $655 \pm 146$ & $589 \pm 106$ & $308 \pm 31$ & $508 \pm 79$ \\
\hline NS & NS & $<0.01$ & $<0.05$ & NS & $<0.05$ & NS & NS & NS \\
\hline
\end{tabular}

$\ddagger+\mathrm{d} P / \mathrm{d} t$-peak positive $\mathrm{d} P / \mathrm{d} t ;-\mathrm{d} P / \mathrm{d} t$-peak negative $\mathrm{d} P / \mathrm{d} t$; EDV-left ventricular end-diastolic volume; ESV-left ventricular end-

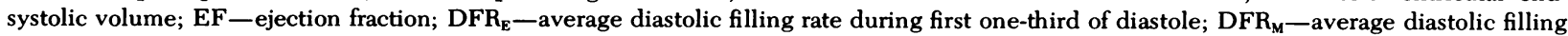
rate during middle one-third of diastole; $\mathrm{DFR}_{\mathrm{L}}$-average diastolic filling rate during last one-third of diastole; $\overline{\mathrm{DFR}}-$ average diastolic filling rate during all of diastole.

Biplane left ventricular cineangiography (PA and LAT) was performed in eight of the study patients and single plane cineangiography (RAO) in three of the study patients (patients 3,4 , and 11, Table I). Biplane cineangiography was performed in the three control subjects with congestive heart failure and single plane cineangiography was performed in the three control subjects with no evidence of organic heart disease. Care was taken to insure that neither the patient nor the equipment was moved between sequential biplane angiograms and that the degree of obliquity was reproduced between sequential RAO angiograms. A movable marker synchronized with the QRS complex of the electrocardiogram was filmed with the cineangiogram and used to identify end diastole. A recording of the electrocardiogram, high fidelity left ventricular pressure, injection marker, and cineangiographic frame markers was made simultaneously with the cineangiogram, and enabled left ventricular pressures to be matched with left ventricular angiographic silhouettes throughout the cardiac cycle (Fig. 1).

Experimental protocol. After placement of the catheters, base-line (control) measurements were made of Fick cardiac output, systemic arterial pressure, pulmonary artery wedge pressure, pulmonary artery pressure, right atrial pressure, high fidelity left ventricular pressure, and the first derivative of left ventricular pressure with respect to time $(\mathrm{d} P / \mathrm{d} t)$. Control left ventricular cineangiography and simultaneous high fidelity left ventricular pressure measurement were then performed. 5-10 min later, after intracardiac pressures had returned to base line, sodium nitroprusside $(50 \mathrm{mg}$ in 1,000 $\mathrm{cm}^{3} D_{5, w}$ ) was infused to lower mean arterial pressure approximately $20-30 \mathrm{~mm} \mathrm{Hg}$, and this state was maintained for 20 min. Fick cardiac output, intracardiac pressure measurements, and left ventricular cineangiography were repeated at the end of this period, and then sodium nitroprusside was discontinued. In six control subjects, two left ventricular cineangiograms with high fidelity left ventricular pressure measurements were performed 15 min apart, without nitroprusside infusion to assess the effect of the cineangiogram itself on the diastolic pressure-volume relationship. The high fidelity left ventricular pressure was balanced with the pressure measured through the fluid-filled lumen of the Millar catheter ${ }^{1}$ before and after each cineangiogram to ensure that there was no drift in the high fidelity pressure.

Analysis of data. For each patient, left ventricular angio- 


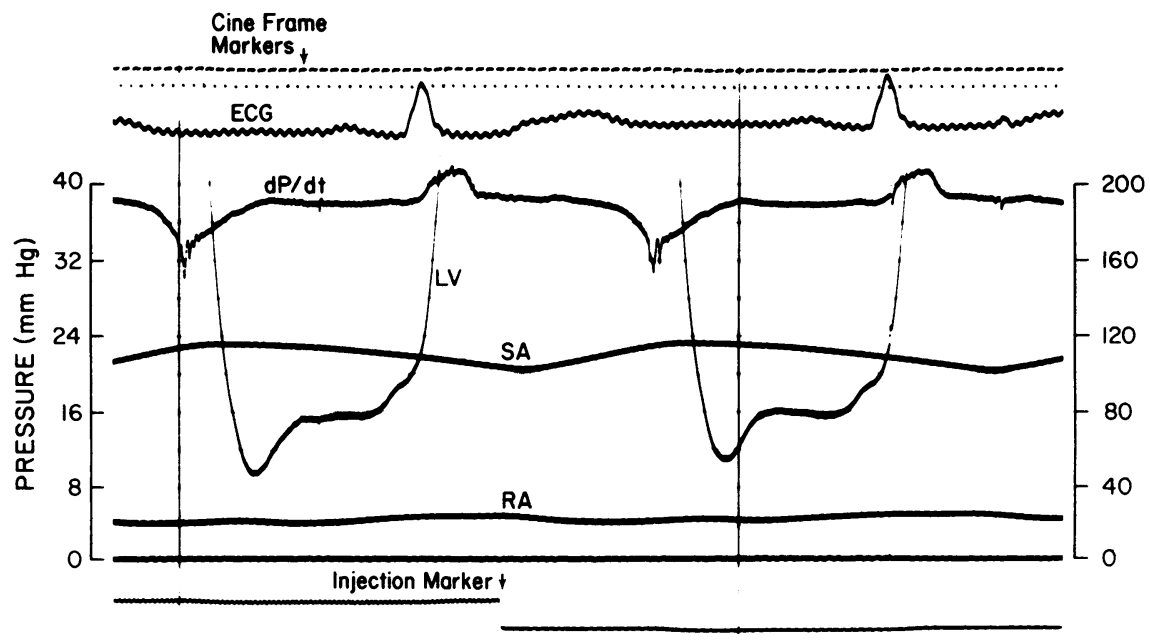

FIgURE 1 The above recording of the electrocardiogram (ECG), high fidelity left ventricular pressure $(\mathrm{LV})$, first derivative of left ventricular pressure with respect to time $(d P / d t)$, mean systemic arterial pressure (SA), mean right atrial pressure (RA), injection marker, and cineangiographic frame markers was made simultaneously with the left ventricular cineangiogram. The injection marker signals the time at which contrast material is injected into the left ventricular chamber and enables cardiac cycles on the pressure tracing to be matched with corresponding cycles on the cineangiogram. The electrocardiogram and cineangiographic frame markers, combined with a moveable marker synchronized with the QRS complex of the ECG and recorded on the cineangiogram, enable left ventricular pressures to be matched with left ventricular angiographic silhouettes throughout each cardiac cycle.

graphic silhouettes were traced every two frames $(36 \mathrm{~ms})$ beginning at end diastole (determined by the movable QRS marker on the cineangiogram) and moving backwards to the beginning of diastole (determined from the smallest ventricular volume). The earliest adequately visualized beats were used, and the first two beats after premature systoles were excluded. High fidelity left ventricular pressures, recorded simultaneously with the cineangiogram, were matched with left ventricular angiographic silhouettes as shown in Fig. 1. Left ventricular volumes were calculated using the area-length method (15) and a grid calibration technique with the help of a sonic digitizer (Science Assessories Corp., Southport, Conn.) interfaced to a programmable calculator (Wang Laboratories, Inc., Tewksbury, Mass.). Interobserver variation in the measurement of volumes by this technique was found to be less than $4 \%$. Pressure-volume curves were constructed throughout diastole for each patient in the control state and during sodium nitroprusside infusion, as well as for the six patients to whom no sodium nitroprusside was given.

Diastolic filling rates were calculated as the change in calculated ventricular volume during diastole divided by the time over which this change occurred as determined from the number of cineangiographic frames elapsed. Diastolic filling rates were measured during the first, middle, and last thirds of diastole and for total diastole both during the control state and during nitroprusside infusion.

Comparisons of hemodynamic and angiographic parameters between the control period and sodium nitroprusside infusion were made using a paired $t$ test. Differences were labeled as significant when $P$ values were $\leq 0.05$.

\section{RESULTS}

In 9 of 11 patients, infusion of sodium nitroprusside resulted in a definite downward shift of the left ventric- ular diastolic pressure-volume relationship. An example of one of these patients who showed a distinct shift of the curve is shown in Fig. 2; the diastolic pressure is lower for any given volume during nitroprusside infusion. The pressure-volume curres of the other 10 patients are shown in Fig. 3. One patient (no. 10) showed only a very small shift and one patient (no. 11) showed no downward displacement of the pressure-volume curve with nitroprusside. The pattients with the highest left ventricular diastolic pressures during the control period tended to show the largest shifts in their pressure-volume curves. The six control patients who had two serial left ventricular cineangiograms performed $15 \mathrm{~min}$ apart without nitroprusside infusion showed essentially no change in their diastolic pressure-volume curves (Fig. 4), indicating that the angiogram itself did not alter the diastolic pressure-volume relationship.

Hemodynamic and angiographic data are presented in Table I. Systemic vascular resistance, mean systemic arterial pressure, left ventricular end-diastolic pressure, left ventricular minimal diastolic pressure, mean pulmonary artery wedge pressure, mean pulmonary artery pressure, and mean right atrial pressure all fell significantly with nitroprusside while heart rate did not change. Cardiac output increased and pulmonary vascular resistance decreased with nitroprusside infusion but these changes were not statistically significant. Both peak positive $\mathrm{d} P / \mathrm{d} t$ and peak negative $\mathrm{d} P / \mathrm{d} t$ fell significantly with nitroprusside. The left 
ventricular end-diastolic and end-systolic volume decreased significantly while the ejection fraction did not change significantly. The diastolic filling rate decreased during the first third of diastole, did not change during the middle third of diastole and decreased slightly, but not significantly, during the last third of diastole.

\section{DISCUSSION}

Our results indicate that sodium nitroprusside is capable of producing a substantial downward displacement of the left ventricular diastolic pressure-volume relationship. This displacement does not appear to be the result of serial left ventricular cineangiography itself, since patients having serial angiograms without nitroprusside infusion did not show this shift. There are several possible explanations for our findings and these can be considered by examining the factors governing the behavior of the left ventricle in diastole (16). These factors are: $(a)$ completeness of left ventricular relaxation; (b) viscoelastic and plastic properties of the left ventricle; $(c)$ inertial properties and diastolic suction; and $(d)$ properties extrinsic to the left ventricle, e.g. pericardial properties, right ventricular loading, aortic root, and coronary artery factors, pleural pressure.

The importance of left ventricular relaxation has been disputed for some time (17) but there is evidence that an impairment in relaxation may be important in certain pathological conditions (18-20). Patients with congestive heart failure from primary myocardial disease, for example, have a diminished rate of fall of the left ventricular pressure (peak negative $d P / d t$ ) compared with control patients suggesting impaired left ventricular relaxation (18). The rate of fall of left ventricular pressure is also reduced in patients with ischemic heart disease in response to pacing induced angina (19), and these patients may develop alterations in their ventricular diastolic pressure-volume relationships (20). We measured the derivative of left ventricular pressure with respect to time before and during sodium nitroprusside infusion in our patients in an attempt to assess the influence of nitroprusside on left ventricular relaxation. Both peak positive and peak negative $d P / d t$ fell slightly but not significantly with nitroprusside. The reduction in arterial pressure with nitoprusside in our patients could account for a fall in peak negative $d P / d t(21,22)$, obscuring or cancelling any changes in the opposite direction due to improved left ventricular relaxation. Positive $d P / d t$ is only slightly influenced by changes in afterload $(22,23)$.

Sodium nitroprusside could potentially influence left ventricular relaxation by several mechanisms. Nitroprusside may improve relaxation by reducing myocardial ischemia. Sodium nitroprusside reduces ventricular preload and afterload and this may reduce

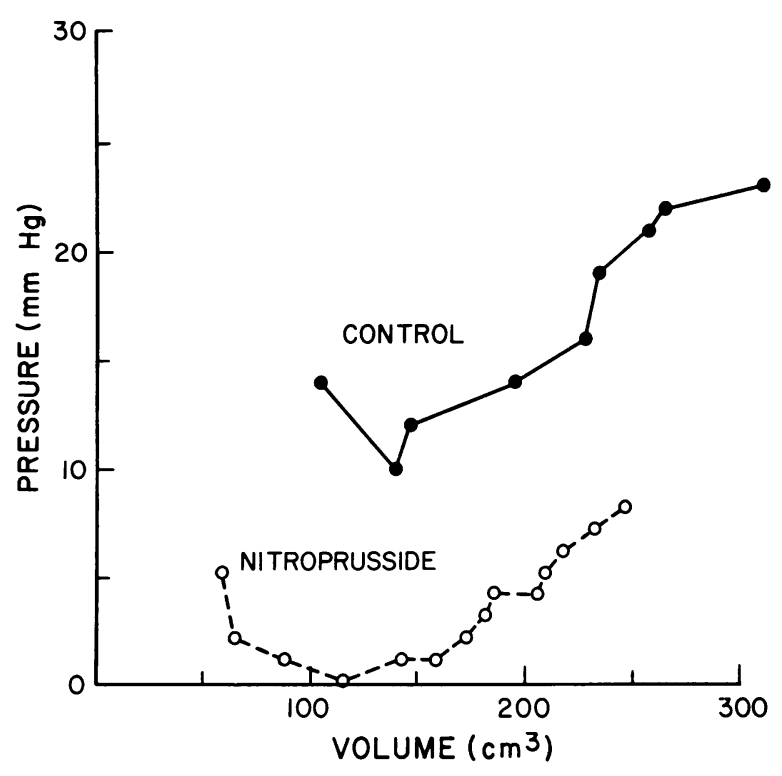

FIGURE 2 Pressure-volume relationships in a patient with rheumatic heart disease and mitral regurgitation. There is a substantial downward displacement of the pressure-volume curve during sodium nitroprusside infusion, with left ventricular pressure being lower for any given volume with nitroprusside. Hemodynamic and angiographic data for this patient (patient 1 ) are shown in Table I.

myocardial ischemia by favorably influencing the balance between myocardial oxygen supply and demand $(24,25)$. This does not seem to be a likely explanation in our patients, since our patients had no evidence of ischemic heart disease.

Secondly, nitroprusside may influence left ventricular relaxation by causing reflex changes in the autonomic nervous system and stimulating catecholamine release. Parmley and Sonnenblick observed that isoproterenol enhanced myocardial relaxation in isolated muscle studies (26) and Morad and Rolett found that catecholamines reduced the contracture tension induced by $\mathrm{KCl}$ in mammalian heart muscle (27). In left ventricular experimental preparations, there is conflicting evidence concerning the effect of catecholamines on left ventricular relaxation. Katz et al. found a slight "increase in ventricular diastolic tone" with norepinephrine (28) while Rushmer found increased diastolic distensibility with epinephrine (29). Mitchell et al. studied the pressure-segment length relationship in dogs during pacing induced tachycardia and found evidence of incomplete left ventricular relaxation at fast heart rates which was improved with stellate ganglion stimulation (30). In our study, nitroprusside reduced systemic arterial pressure and this could potentially increase sympathetic nervous system activity through baroreceptor reflex changes. This might result in improved ventricular relaxation and could bear some relationship to the downward 


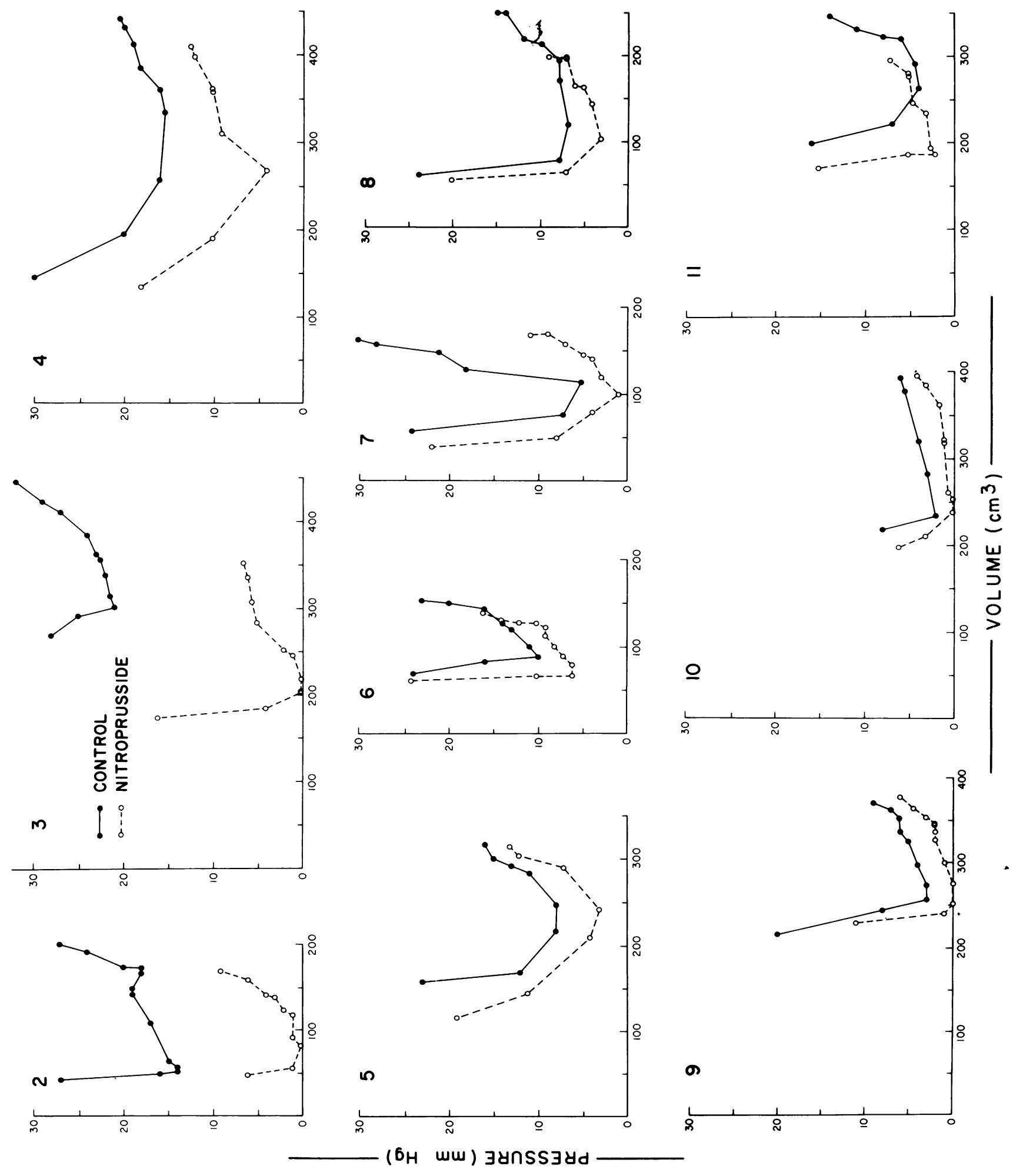



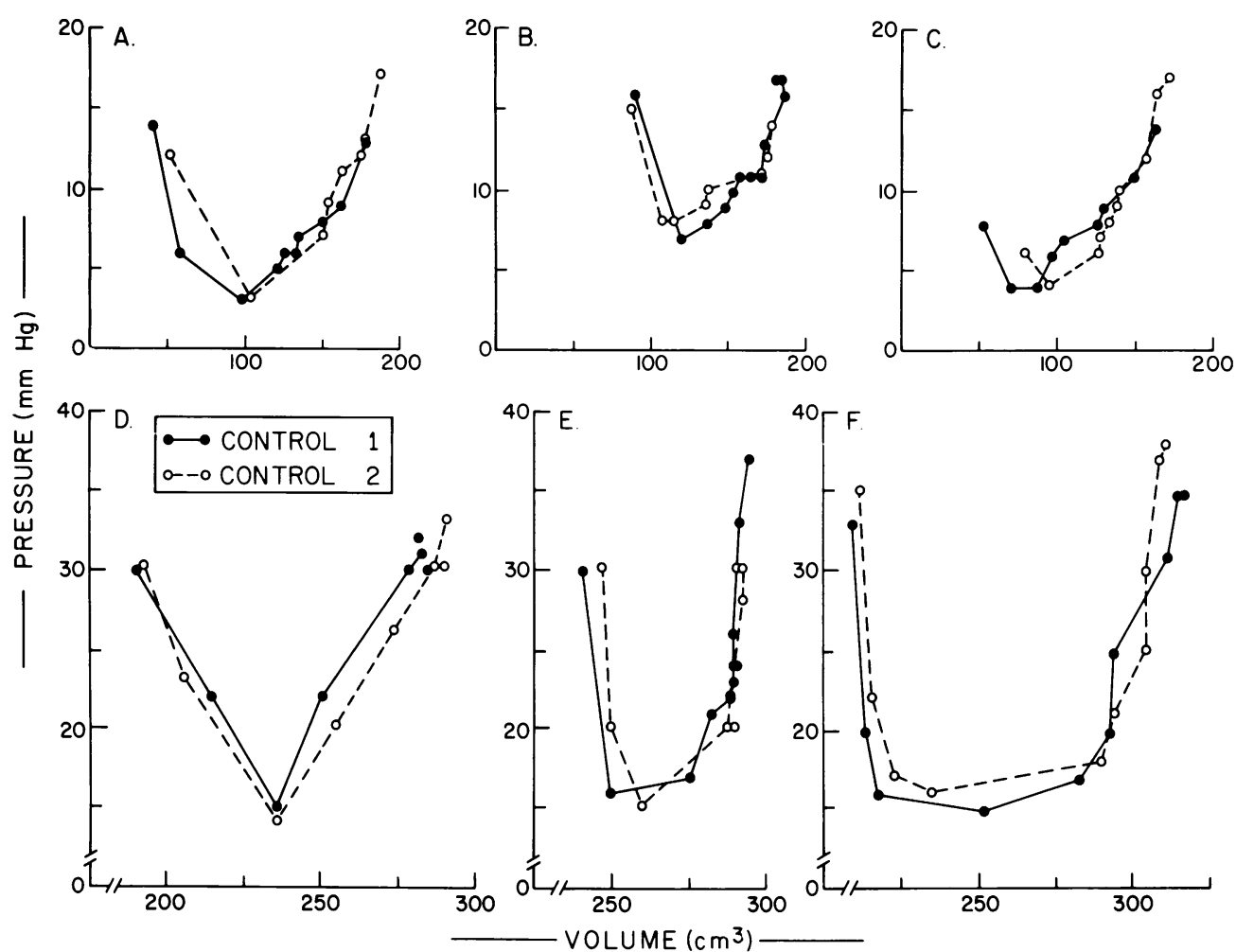

Figure 4 Pressure-volume curves in six patients who underwent serial left ventricular cineangiography 15 min apart but did not receive sodium nitroprusside. The curves shown in A, B and C are from patients with chest pain syndromes and angiographically normal coronary arteries and normal hemodynamics and the curves shown in D, E, and F are from patients with congestive heart failure. In each subject there is no apparent difference between the first and second pressurevolume curves, indicating that the angiographic procedure itself was not responsible for the changes in the diastolic pressure-volume relationship seen with nitroprusside.

shift of the pressure-volume curves in our patients. This mechanism seems unlikely since there was no change in heart rate with nitroprusside suggesting there was little change in sympathetic nervous system activity.

Thirdly, nitroprusside might exert a direct relaxant effect on cardiac muscle similar to its known relaxant effect on vascular smooth muscle (24). This has recently been studied in isolated muscle preparations (31). When cat papillary muscles are made hypoxic and then reoxygenated, there is a marked prolongation of tension, both the time to peak tension and the time for tension to fall to one-half its peak value $(32,33)$. This tension prolongation was substantially reduced in muscles pretreated with $10^{-5} \mathrm{M}$ sodium nitroprusside.
However, nitroprusside had no effect on the duration of tension in nonhypoxic muscles and had no effect on resting tension. Whether these data obtained with hypoxic muscle preparations relates to our human studies is uncertain, but it does suggest that nitroprusside may be capable of influencing the myocardial relaxation process under hypoxic conditions.

As shown in Figs. 2 and 3, patients with the highest diastolic pressures tended to show the largest shifts in the diastolic pressure-volume relationship, and two of the three patients with the lowest diastolic pressures showed little or no shift with nitroprusside. This observation is consistent with the possibility that nitroprusside might improve left ventricular relaxation and that this effect might be most pronounced in those

FIgURE 3 Pressure-volume curves in 10 patients before and during the administration of sodium nitroprusside. There is a substantial downward displacement of the pressure-volume curves with nitroprusside infusion in patients 2-9. Patient 10 showed only a small displacement and patient 11 did not show any downward shift of the pressure-volume curve during nitroprusside infusion. Hemodynamic and angiographic data for each patient are shown in Table $\mathrm{I}$. 
patients with elevated diastolic pressures due to incomplete relaxation.

A second possible explanation for the shift in the pressure-volume curves is that nitroprusside may alter viscoelastic properties of the left ventricle. Viscous drag may result in a greater rise in ventricular pressure when blood enters the ventricle rapidly than when blood enters the ventricle slowly. Noble et al. (34) in studies with close-chested dogs found that isoproterenol and methoxamine infusion altered the relationship between left ventricular diastolic pressure and diameter during periods of rapid filling and concluded that these changes were due to viscous forces. Rankin et al. in close-chested dog experiments (35) and Gaasch et al. in human studies (36) found that the diastolic pressure-volume curve deviated from the exponential curve of best fit during periods of rapid filling in early diastole and at the time of atrial contraction and concluded that viscous forces were important during these periods. In our study, diastolic filling rates fell significantly during the first third of diastole, did not change during the middle third of diastole, and fell slightly, but not significantly, during the last third of diastole (Table I). These changes in filling rates may contribute to the shifts in the diastolic pressure-volume curves seen in our patients. It is unlikely that this is the only explanation because in most cases the diastolic pressure-volume curves with nitroprusside were displaced from the control curves not only in early diastole but also in middle and late diastole when there was little change in the filling rates. Also, diastolic filling rates increased slightly with nitroprusside in patient 4 (Table I), yet the pressure-volume curve shifted downward similar to the other patients.

Closely related to viscoelastic properties are plastic properties of the left ventricle which are the slow time-dependent changes in the physical properties of the muscle that may occur after exposure to prolonged stretch. Studies with isolated cardiac muscle and isolated heart preparations (37-41) have shown that when cardiac muscle is suddenly exposed to increased tension (either systolic or diastolic) and length is held constant, there is a gradual fall in resting tension ("stress relaxation"). If the muscle is suddenly exposed to decreased tension, and length is then held constant, there is a gradual increase in resting tension. Alternatively, if the muscle is exposed to an increased tension and tension is then held constant, there may be a gradual increase in resting length ("creep") or if the muscle is exposed to a decreased tension and tension is held constant, there may be a gradual decrease in resting length. The clinical importance of these phenomena is uncertain, but they cannot explain the changes in the pressure-volume curves seen in our patients. Nitroprusside reduced left ventricular systolic and diastolic blood pressure in our patients and this would result in a gradual increase in left ventricular diastolic pressure at constant volume or a gradual decrease in diastolic volume at constant pressure. These changes would shift the diastolic pressurevolume curve upward rather than downward as was observed.

A third possibility is that nitroprusside may alter inertial properties or diastolic suction. Inertial forces are very difficult to identify and measure and there is little evidence that they are of any practical importance (34). The importance of diastolic suction is disputed $(42,43)$. Diastolic suction may result when the left ventricle contracts to a volume smaller than its elastic equilibrium volume, and then rebounds by elastic recoil to cause a negative pressure or suction effect. By this concept, suction should occur only in early diastole when the ventricle is smaller than its elastic equilibrium volume, and the amount of suction should be dependent only upon the elastic properties of the ventricle and the ventricular volume. The possible effects of sodium nitroprusside on diastolic suction cannot be evaluated from the present study.

Finally, nitroprusside may affect the diastolic pressure-volume relationship by altering one or more of several extrinsic constraints acting upon the left ventricle. These constraints include the pericardium, the right ventricle, the pleural pressure, and the aortic root and coronary arteries. The pericardium probably offers no restriction to left ventricular filling under normal conditions but it may be capable of exerting a restrictive function when the heart is distended to large volumes $(44,45)$. While nitroprusside may diminish pericardial restriction by reducing ventricular volumes, the amount of pericardial restriction and its influence on the left ventricular pressure remains a unique function of the left ventricular volume, and the entire diastolic pressure-volume curve should not be affected.

The influence of right ventricular loading upon the left ventricle has been studied in dogs by several observers (46-48). Elevations of right ventricular filling pressures may cause an upward shift in the left ventricular diastolic pressure-volume curve so that the left ventricular pressure is higher at a given volume. The converse of this is that a reduction in right ventricular filling pressures may cause a downward shift in the left ventricular pressurevolume curve. Since nitroprusside reduced right heart pressures in our patients, this mechanism may be an important factor. Somewhat against this being the only factor is that significant shifts in the left ventricular diastolic pressure-volume relationship occurred in patients $3-5$, in whom there was little or no change in the right ventricular filling pressure.

The influence of nitroprusside on pleural pressures 
is unknown. Nitroprusside decreased the pulmonary artery wedge pressures in our patients and it is possible that this could have resulted in a reduction in pleural pressures. If this were so, the pressurevolume curve would be shifted downward.

A remaining possibility is that the pressure in the aortic root and coronary arteries may influence the left ventricular diastolic pressure-volume relationship. It is possible that the aortic root may impinge more or less upon the left ventricular chamber depending upon the aortic root pressure, and that decreases in aortic pressure may be capable of shifting the pressurevolume curve downward. Likewise, the pressure and blood flow in the coronary arteries and their intramural branches could affect the compliance of the left ventricular wall and influence the pressure-volume curve on this basis. This possibility is supported by the work of Salisbury et al. (49) who studied the influence of coronary artery perfusion pressure on the left ventricular end-diastolic pressure in dogs undergoing cardiopulmonary bypass. The coronary arteries were cannulated and the contracting left ventricles were distended with intracavitary balloons and held at constant volume. Increases in coronary artery perfusion pressure resulted in increases in left ventricular end-diastolic pressures with left ventricular volume held constant suggesting reduced left ventricular compliance, and decreases in coronary artery perfusion pressure decreased left ventricular enddiastolic pressures at constant volume suggesting increased left ventricular compliance.

In summary, our results indicate that nitroprusside is capable of producing a substantial downward displacement of the left ventricular diastolic pressurevolume relationship. There are several possible explanations for the findings and the most likely appear to be that nitroprusside either improves left ventricular relaxation, affects left ventricular viscous properties or alters one or more of the external constraints acting upon the left ventricle. The improved ventricular compliance seen with nitroprusside administration in our patients suggests another potential benefit of this type of therapy in the treatment of patients with congestive heart failure.

\section{ACKNOWLEDGMENTS}

The authors are grateful for the very helpful technical assistance of Mr. Donald Jones and Mr. Conley Hobbie and the excellent secretarial assistance of Ms. Sara Spinks and Ms. Nancy Rogers.

This work was supported by U. S. Public Health Service Award T01 HL05727-09, National Heart and Lung Institute grants and North Carolina United Community Services.

\section{REFERENCES}

1. Schlant, R. C., T. S. Tsagaris, and R. J. Robertson, Jr.
1962. Studies on acute cardiovascular effects of intravenous sodium nitroprusside. Am. J. Cardiol. 9: 51-59.

2. Page, I. H., A. C. Corcoran, H. P. Dustan, and T. Koppanyi. 1955. Cardiovascular actions of sodium nitroprusside in animals and hypertensive patients. Circulation. 11: $118-198$.

3. Mani, M. K. 1971. Nitroprusside revisited. Br. Med. J. 3: 407-408.

4. Ahearn, D. J., and C. E. Grim. 1974. Treatment of malignant hypertension with sodium nitroprusside. Arch. Intern. Med. 133: 187-191.

5. Franciosa, J. A., N. H. Guiha, C. J. Limas, E. Rodriguera, and J. N. Cohn. 1972. Improved left ventricular function during nitroprusside infusion in acute myocardial infarction. Lancet. 1: 650-654.

6. Chatterjee, K., W. W. Parmley, W. Ganz, J. Forrester, P. Walinsky, C. Crexells, and H. J. C. Swan. 1973. Hemodynamic and metabolic responses to vasodilator therapy in acute myocardial infarction. Circulation. 48: 1183-1193.

7. Chatterjee, K., W. W. Parmley, H. J. C Swan, G. Berman, J. Forrester, and H. S. Marcus. 1973. Beneficial effects of vasodilator agents in severe mitral regurgitation due to dysfunction of subvalvular apparatus. Circulation. 48: 684-690.

8. Goodman, D. J., R. M. Rossen, E. L. Holloway, E. L. Alderman, and D. C. Harrison. 1974. Effect of nitroprusside on left ventricular dynamics in mitral regurgitation. Circulation. 50: 1025-1032.

9. Grossman, W., C. W. Harshaw, A. B. Munro, L. Becker, and L. P. McLaurin. 1974. Lowered aortic impedance as therapy for severe mitral regurgitation. J. Am. Med. Assoc. 230: 1011-1013.

10. Harshaw, C. W., W. Grossman, A. B. Munro, and L. P. McLaurin. 1975. Reduced systemic vascular resistance as therapy for severe mitral regurgitation of valvular origin. Ann. Intern. Med. 83: 312-316.

11. Bolen, J. L., and E. L. Alderman. 1976. Hemodynamic consequences of afterload reduction in patients with chronic aortic regurgitation. Circulation. 53: 879-883.

12. Guiha, N. H., J. N. Cohn, E. Mikulic, J. A. Franciosa, and C. J. Limas. 1974. Treatment of refractory heart failure with infusion of nitroprusside. N. Engl. J. Med. 291: 587-592.

13. Miller, R. R., L. A. Vismara, R. Zelis, E. A. Amsterdam, and D. T. Mason. 1975. Clinical use of sodium nitroprusside in chronic ischemic heart disease. Effects on peripheral vascular resistance and venous tone and on ventricular volume, pump and mechanical performance. Circulation. 51: 328-336.

14. Adams, A. P., T. N. S. Clarke, J. Edmonds-Seal, P. Foëx, C. Prys-Roberts, and J. Roberts. 1973. Effects of sodium nitroprusside on myocardial contractility and haemodynamics. Br. J. Anaesth. 45: 120. (Abstr.)

15. Dodge, H. T., H. Sandler, D. W. Ballew, and J. D. Lord, Jr. 1960. Use of biplane angiocardiography for the measurement of left ventricular volume in man. Am. Heart J. 60: 762-776.

16. Grossman, W., and L. P. McLaurin. 1976. Diastolic properties of the left ventricle. Ann. Intern. Med. 84: 316-326.

17. Meek, W. J. 1927. The question of cardiac tonus. Physiol. Rev. 7: 259-287.

18. McLaurin, L. P., E. L. Rolett, and W. Grossman. 1974. Defective left ventricular relaxation in congestive heart failure. Circulation. 50(Suppl. III): III-45. (Abstr.)

19. McLaurin, L. P., E. L. Rolett, and W. Grossman. 1973. 
Impaired left ventricular relaxation during pacinginduced ischemia. Am. J. Cardiol. 32: 751-757.

20. Barry, W. H., J. Z. Brooker, E. L. Alderman, and D. C. Harrison. 1974. Changes in diastolic stiffness and tone of the left ventricle during angina pectoris. Circulation. 49: 255-263.

21. Weisfeldt, M. L., H. E. Scully, J. Frederiksen, J. J. Rubenstein, G. M. Pohost, E. Beierholm, A. G. Bello, and W. M. Daggett. 1974. Hemodynamic determinants of maximum negative $\mathrm{dP} / \mathrm{dt}$ and periods of diastole. Am. J. Physiol. 227: 613-621.

22. Cohn, P. F., A. J. Liedtke, J. Serur, E. H. Sonnenblick, and C. W. Urschel. 1972. Maximum rate of pressure fall (peak negative $\mathrm{dP} / \mathrm{dt}$ ) during ventricular relaxation. Cardiovasc. Res. 6: 263-267.

23. Mahler, F., J. Ross, Jr., R. A. O'Rourke, and J. W. Covell. 1975. Effects of changes in preload, afterload and inotropic state on ejection and isovolumic phase measures of contractility in the conscious dog. Am. J. Cardiol. 35: 626-634.

24. Palmer, R. F., and K. C. Lasseter. 1975. Drug therapy: Sodium nitroprusside. N. Engl. J. Med. 292: 294-297.

25. Da Luz, P. L., J. S. Forrester, H. L. Wyatt, J. V. Tyberg, R. Chagrasulis, W. W. Parmley and H. J. C. Swan. 1975. Hemodynamic and metabolic effects of sodium nitroprusside on the performance and metabolism of regional ischemic myocardium. Circulation. 52: 400-407.

26. Parmley, W. W., and E. H. Sonnenblick. 1969. Relation between mechanics of contraction and relaxation in mammalian cardiac muscle. Am. J. Physiol. 216: 1084- 1091.

27. Morad, M., and E. L. Rolett. 1972. Relaxing effects of catecholamines on mammalian heart. J. Physiol. (Lond.). 224: 537-558.

28. Katz, A. M., L. N. Katz, and F. L. Williams. 1955. Registration of left ventricular volume curves in the dog with the systemic circulation intact. Circ. Res. 3: 588-593.

29. Rushmer, R. F. 1956. Pressure-circumference relations of left ventricle. Am. J. Physiol. 186: 115-121.

30. Mitchell, J. H., R. J. Linden, and S. J. Sarnoff. 1960. Influence of cardiac sympathetic and vagal nerve stimulation on the relation between left ventricular diastolic pressure and myocardial segment length. Circ. Res. 8: $1100-1107$.

31. Brodie, B. R., L. Chuck, S. Klausner, W. Grossman, and W. W. Parmley. 1976. Effects of sodium nitroprusside and nitroglycerin on tension prolongation during recovery from hypoxia. Circ. Res. 39: 596-601.

32. Tyberg, J. V., L. A. Yeatman, W. W. Parmley, C. W. Urschel, and E. H. Sonnenblick. 1970. Effects of hypoxia on mechanics of cardiac contraction. Am. J. Physiol. 218: $1780-1788$.

33. Bing, O. H. L., J. F. Keefe, M. J. Wolk, L. J. Finkelstein, and H. J. Levine. 1971. Tension prolongation during recovery from myocardial hypoxia. J. Clin. Invest. 50: 660-666.

34. Noble, M. I. M., E. N. C. Milne, R. J. Goerke, E. Carlsson, R. J. Domenech, K. B. Saunders, and J. I. E. Hoffman. 1969. Left ventricular filling and diastolic pressurevolume relations in the conscious dog. Circ. Res. 24: 269-283.

35. Rankin, J. S., C. E. Arentzen, R. W. Anderson and P. A. McHale. 1975. Viscoelastic properties of the diastolic left ventricle. Circulation. 52(Suppl. II): II-35. (Abstr.)

36. Gaasch, W. H., J. S. Cole, M. A. Quinones, and J. K. Alexander. 1975. Dynamic determinants of left ventricular diastolic pressure-volume relations in man. Circulation. 51: 317-323.

37. Sonnenblick, E. H., J. Ross, Jr., J. W. Covell, and E. Braunwald. 1966. Alterations in resting length-tension relations of cardiac muscle induced by changes in contractile force. Circ. Res. 19: 980-988.

38. Little, R. C., and W. B. Wead. 1971. Diastolic viscoelastic properties of active and quiescent cardiac muscle. Am. J. Physiol. 221: 1120-1125.

39. Alexander, R.S. 1962. Viscoelastic determinants of muscle contractility and "cardiac tone". Fed. Proc. 21: 1001-1005.

40. Covell, J. W., and J. Ross, Jr. 1973. Nature and significance of alterations in myocardial compliance. Am. J. Cardiol. 32: 449-455.

41. Monroe, R. G., C. G. La Farge, W. J. Gamble, A. Rosenthal, and S. Honda. 1968. Left ventricular pressure-volume relations and performance as affected by sudden increases in developed pressure. Circ. Res. 22: 333-344.

42. Brecher, G. A. 1956. Experimental evidence of ventricular diastolic suction. Circ. Res. 4: 513-518.

43. Guyton, A. C., C. E. Jones, and T. G. Coleman. 1973. Circulatory Physiology: Cardiac Output and Its Regulation. W. B. Saunders Company, Philadelphia. 2nd edition. $157,178$.

44. Holt, J. P., E. A. Rhode, and H. Kines. 1960. Pericardial and ventricular pressure. Circ. Res. 8: 1171-1181.

45. Holt, J. P. 1970. The normal pericardium. Am. J. Cardiol. 26: 455-465.

46. Taylor, R. R., J. W. Covell, E. H. Sonnenblick, and J. Ross, Jr. 1967. Dependence of ventricular distensibility on filling of the opposite ventricle. Am. J. Physiol. 213: $711-718$.

47. Laks, M. M., D. Garner, and H. J. C. Swan. 1967. Volumes and compliances measured simultaneously in the right and left ventricles of the dog. Circ. Res. 20: 565-569.

48. Kelly, D. T., H. M. Spotnitz, G. D. Beiser, J. E. Pierce, and S. E. Epstein. 1971. Effects of chronic right ventricular volume and pressure loading on left ventricular performance. Circulation. 44: 403-412.

49. Salisbury, P. F., C. E. Cross, and P. A. Rieben. 1960 Influence of coronary artery pressure upon myocardial elasticity. Circ. Res. 8: 794-800. 